ИЗВЕСТИЯ АКАДЕМИИ НАУК ЭСТОНСКОИ ССР. ТОМ 22 ХИМИЯ * ГЕОЛОГИЯ. 1973, № 3

\title{
О ПОЗДНЕ- И ПОСЛЕЛЕДНИКОВЫХ ДВИЖЕНИЯХ ЗЕМНОЙ КОРЫ НА ТЕРРИТОРИИ ЭСТОНИИ
}

В последнее десятилетие представления Х. Хаузена (Hausen, 1913) и В. Рамзея (Ramsay, 1929) о поздне- и послеледниковых движениях земной коры в Эстонии нашли дальнейшее развитие в работах К. Орвику $(1960,1969)$, Х. Кессел (1961), Х. Кессел и Я. М. Пуннинга (1969 а, б), Х. Кессел и А. Раукаса (1967), К. Пярна (1962) и др., при этом главным источником соответствующих данных были древние береговые образования приледниковых озер и Балтийского моря.

В итоге к настоящему времени на территории Эстонии установлено 6 серий древних береговых образований (рис. 1), которые, начиная с
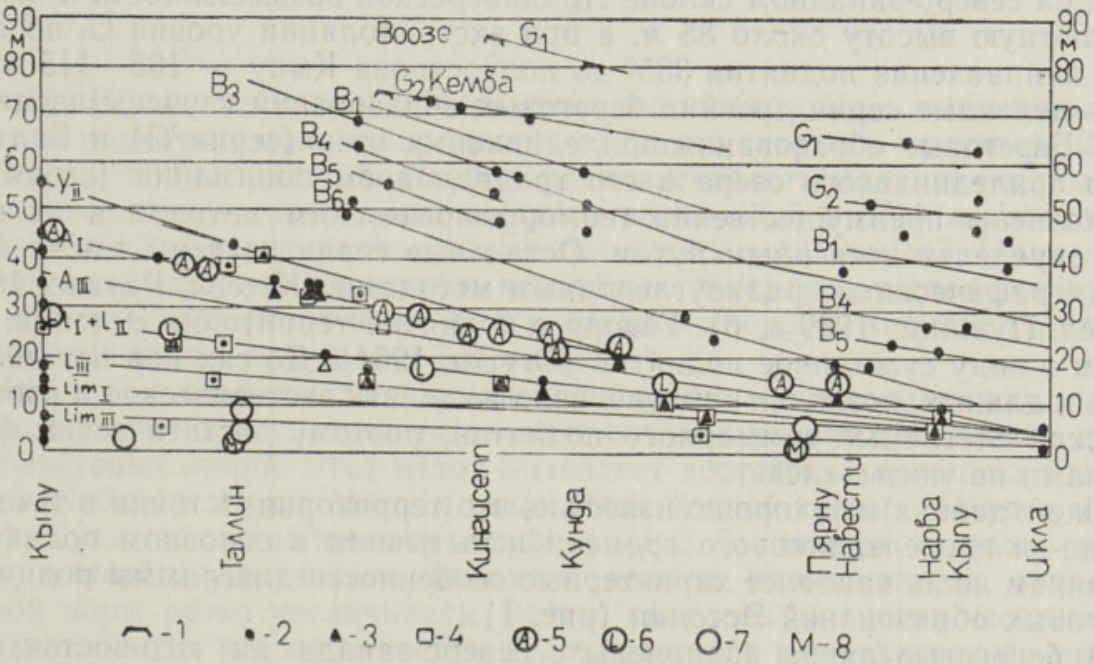

Рис. 1. Диаграмма поднятия береговых образований.

Условные обозначения: $t$ - водноледниковые дельты; 2 - древние береговые образования; 3 - погребенные под береговыми отложениями континентальные органогенные отложения; 4 - спорово-пыльцевой анализ; 5-7 местонахождение субфоссильной малакофауны: 5 - Анцилового озера, 6 - Литоринового моря, 7 - Лимниевого моря; 8 - находка субфоссильных створок муа arenaria. Уровни водоемов: $\mathrm{G}$ - приледниковых озер, В - Балтийского приледникового озера, у - Иольдиевого моря, А - Анцилового озера, L - Литоринового моря и Lim - Лимниевого моря. 


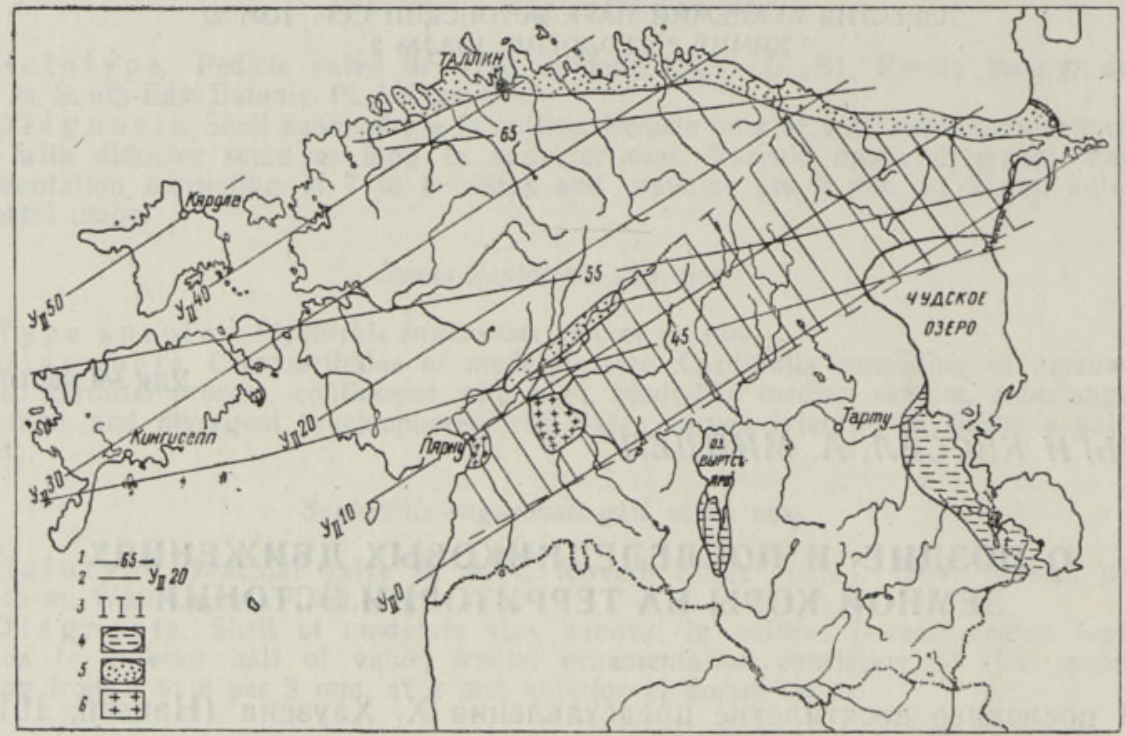

Рис. 2. Схема суммарного поднятия земной коры.

Условные обозначения: $I$ - изолинни поднятия в позднеледниковое время (в $\mu$ ); $2-$ нзолинии поднятия в послеледниковое время (в $s) ; 3$ - предполагаемая шарнирная полоса; 4 - врезание рек в позднеледниковое время и накопленне аллювиально-озерных и болотных отложений в послеледниковое время; 5 - врезание рек в послеледниковое время и признаки врезания в бассейне р. Пярну; 6 - признаки накопления аллювия в послеледниковое время в бассейне р. Пярну.

более древних, обозначены буквами G, B, У, A, L и Lim. Самые высокие из них - береговые образования приледникового озера $\mathrm{G}_{1}$ - расположены на северо-западном склоне Пандивереской возвышенности и имеют абсолютную высоту около $85 \mathrm{M}$, а при экстраполяции уровня $\mathrm{G}_{1}$ по азимуту направления поднятия $335^{\circ}$ до полуострова Кыпу - 105-115 м.

Выделенные серии древних береговых образований изучены неодинаково. Береговые образования приледниковых озер (серия G) и Балтий. ского приледникового озера в его традиционном понимании (серия В) установлены преимущественно геоморфологическим методом и их возраст определен косвенным путем. Остальные серии изучены также биостратиграфическим и радиоуглеродным методами (Кессел, Раукас, 1967; Кессел, Пуннинг, 1969 а, б). Говоря о поднятии территории Эстонии, мы имеем в виду суммарное поднятие (Orviku, 1961). До сих пор нет достоверных данных, позволяющих уверенно выделить эвстатическое и изостатическое слагаемые суммарного поднятия, поэтому эвстатический фактор нами не учитывался.

Уже с давних пор хорошо известно, что территория Әстонии в течение поздне- и послеледникового времени испытывала в основном поднятие. Упомянем лишь наиболее характерные особенности диаграммы поднятия береговых образований Эстонии (рис. 1):

1) береговые линии наклонены с северо-запада на юго-восток, что указывает на уменьшение величины и скорости поднятия в этом направлении;

2) наклон (и соответственно градиент) по мере перехода к более молодым береговым линиям уменьшается, что указывает на уменьшение скорости поднятия во времени.

Эти данные подтверждаются составленной нами схемой суммарного поднятия земной коры (рис. 2). Начиная со времени 'образования при- 
номерно - периоды более быстрого поднятия чередовались с периодами более медленного поднятия, как это и предполагал К. Орвику (1960).

Однако поднятие было неравномерным не только во времени, но и в пространстве, по крайней мере - в позднеледниковое время. Это доказывается изгибом береговых линий Балтийского приледникового озера (рис. 1) в Средней Әстонии, приблизительно по линии г. Пярну - р. Навести - г. Нарва (Пярна, 1962). К северо-западу от этой шарнирной линии, или полосы, интенсивность поднятия была значительно большей, чем к юго-востоку от нее. Так как расположение этой полосы в общих чертах совпадает с тектоническими нарушениями в кристаллическом фундаменте и палеозойских породах, предполагается (Орвику, 1960, 1969), что в позднеледниковое время происходило оживление последних, которое и привело к изменению градиента береговых линий Балтийского приледникового озера. Градиенты более молодых береговых линий, по имеющимся данным, в шарнирной полосе не изменяются, это как будто указывает на равномерное уменьшение поднятия на территории Эстонии в послеледниковое время. Однако по данным повторных нивелировок установлено, что слабые движения земной коры происходят вдоль шарнирной полосы и в настоящее время (Уттер, 1964; Zhelnin, 1966 и др.). Поэтому нам кажется вероятной тектоническая мобильность этой зоны и в голоцене. Доказать это путем изучения голоценовых береговых образований Балтийского моря в Юго-Западной и Северо-Восточной Эстонии весьма трудно, поскольку убывание скорости поднятия соответственно увеличивает относительное влияние эвстатического поднятия уровня моря в юго-восточном направлении. Ввиду этого изменения градиентов голоценовых береговых линий в шарнирной полосе незначительны и разновозрастные береговые образования расположены близко друг к другу.

Неравномерный характер поздне-и послеледниковых движений земной коры выражается не только в изменении скорости поднятия и градиентов береговых линий. Об этом говорит также тенденция изменения азимута направления максимального поднятия в течение поздне- и послеледникового времени. В период существования приледниковых озер $\left(\mathrm{G}_{1}, \mathrm{G}_{2}\right.$ и др.) азимут направления поднятия был равен $335^{\circ}$ (Пярна, 1962), во время Балтийского приледникового озера и последующих стадий Балтийского моря $-326^{\circ}$, а в период Лимниевого моря - $315^{\circ}$. Для современных движений земной коры характерен азимут около $310^{\circ}$. Различием азимутов направления поднятия обусловлено, например, разновысотное положение береговых образований приледниковых озер $\mathrm{G}_{1}$ и $\mathrm{G}_{2}$ (рис. 1). Абсолютные высоты береговых образований образуют единые уровни при азимуте направления поднятия $335^{\circ}$. Хотя причины этого явления нам еще не совсем ясны, можно предположить, что оно отражает смещение центра поднятия на запад в связи с сокращением ледникового покрова Фенноскандии, а также постепенное уменьшение роли гляциоизостатического фактора в движениях земной коры. Смещение центра поднятия во времени допускается рядом исследователей (Lundqvist, 1965; Mörner, 1969).

Можно задать вопрос: не свидетельствует ли изменение азимута направления поднятия о возрастающей активности системы меридиональных волнообразных деформаций, выделенных на Русской равнине Ю. Мещеряковым (1965)?

Как известно, Ю. Мещеряков $(1961,1965)$ выделяет на Русской равнине в истории развития молодых движений земной коры два этапа. Первый из них охватывает первую половину голоцена, включая и литориновое время, и характеризуется общим энергичным поднятием территории последнего оледенения с преобладанием гляциоизостатических 
движений. На втором этапе, соответствующем второй половине голоцена (послелиториновый этап), влияние гляциоизостатических движений уменьшилось, что привело к распаду единой области поднятия на ряд областей поднятия и опускания. С послелиториновым этапом Ю. Мещеряков связывает признаки опускания, проявляющиеся в бассейне Чудского озера: Сходные взгляды развиваются также В. Гуделисом, однако период общего гляциоизостатического поднятия, по его данным, продолжался до анцилового-бореального времени (Гуделис, 1972; Gudelis, 1961).

Касающиеся территории Эстонии данные в общих чертах согласуются с выводами названных исследователей. Судя по величине суммарного поднятия (рис. 2), территория Эстонии в период существования приледниковых озер и Балтийского приледникового озера до возникновения Иольдиевого моря ( $\left.\mathrm{Y}_{\mathrm{II}}\right)$ была захвачена общим поднятием.

Во время Балтийского приледникового озера темп поднятия достигал максимальных значений. К этому времени приурочены значительные колебания уровня приледниковых водоемов.

Величина поднятия составляет, как уже сказано, в Северо-Западной Эстонии около 65 м. Какова эта величина в Юго-Восточной Эстонии, пока неизвестно. К. Орвику (1960), говоря о всем поздне- и послеледниковом времени, оценивает ее цифрой 25 м. По Э. Саммету (1965), в районе г. Пскова величина поднятия тоже в течение всего поздне- и послеледникового времени составляет 15-20 м. Так как позднеледниковье характеризуется очень высокими скоростями поднятия, то можно утверждать, что в образовании суммарного поднятия бо́льшая доля выпадает на это время.

Судя по данным Э. Ханга, Э. Линкрус и Т. Либлик (Hang и др. 1964; Liblik, 1966), в позднеледниковое время величина вреза рек Южной Эстонии составляла не менее 40 м. Однако эту величину нельзя полностью отождествлять с суммарным поднятием, потому что развитие рек Южной Эстонии преимущественно зависело от понижения уровня приледниковых озер. Возможно, что в это же время формировалась шарнирная линия (Орвику, 1960), разделившая территорию Эстонии на два крупных блока и обусловившая тот факт, что Юго-Восточная Эстония стала районом относительного опускания.

Согласно некоторым авторам (Хейнсалу, Сильдвээ, 1971 и др.), в позднеледниковое время большая роль в развитии рельефа принадлежала дифференцированным движениям локальных структур. В связи с этим необходимо обратить внимание на несогласованность простираний изобаз поздне- и послеледникового поднятий с простиранием геологических структур, что, по нашему мнению, указывает на индифферентность поднятия по отношению к структурно-геологическому строению. Дифференцированные движения локальных структур должны были отразиться в какой-то мере и в спектрах береговых линий, что, однако, результатами исследований последних лет пока не подтверждено. Кроме того, поскольку местные экзогенные факторы также влияют на формирование береговых образований, к интерпретации последних в целях установления движений локальных структур следует относиться очень осторожно. Например, по А. Хернстену (Hörnsten, 1964), колебания относительных высот береговой линии в зависимости от экспозиции берега волнению даже в пределах очень ограниченных участков могут достигать 10 . Поэтому мы склонны думать, что поздне- и послеледниковые мелкоблоковые движения земной коры в Эстонии имели подчиненное значение, содействуя активизации уже существовавших древних структур и разломов.

Поднятие территории Эстонии продолжалось, хотя и в убывающем 
темпе, также в течение послеледникового времени. На основании изобаз береговых образований Иольдиевого моря ( $\left.\mathrm{Y}_{\text {II }}\right)$ величина поднятия Северо-Западной Эстонии в это время составляла не менее $50 \mu$ (рис. 2). Так как эвстатический фактор неизвестен, невозможно уверенно выделить районы относительного поднятия и опускания. Здесь необходимо отметить, что дно речных долин Южной Әстонии у рек, впадающих с юга в Псковское озеро и оз. Выртсъярв, нередко расположено на $10-15$ м ниже современного уровня этих озер (рис. 2). Этот факт свидетельствует об интенсивном врезании. Время врезания точно не установлено, но предположительно это - или пребореал, или переход от позднего дриаса к пребореалу, когда уровень этих озер сильно понизился (Каяк, 1959; Л. Орвику, 1958; К. Орвику, 1960; Раукас, Ряхни, 1969; Нang и др., 1964 и др.).

Учитывая имеющиеся данные, кажется вероятным, что до атлантического климатического периода вся территория Әстонии испытывала поднятие. Начиная же с атлантического климатического периода, т. е. с началом литоринового времени, а не в послелиториновое время, как предполагает Ю. Мещеряков (1961), в южной части Чудско-Псковского озера заметна тенденция к слабому опусканию (Орвику, 1969). Это выражается прежде всего в заболачивании южной части низины ЧудскоПсковского озера. В устье р. Суур-Эмайыги, где мощность торфа достигает 6 м, этот процесс, по П. Томсону (Thomson, 1939), начался именно в атлантическом климатическом периоде. Кроме того, многие долины рек, впадающих в названные озера с юга (рис. 2), имеют аллювиальные отложения мощностью до 10-15 м (Орвику, 1960, 1969; Мийдел, 1966). То же самое наблюдается в нижнем течении р. Вяйке-Эмайыги, впадающей в оз. Выртсъярв (Каяк, 1959). Вероятно, что начало интенсивной аккумуляции аллювиальных отложений в долинах рек, впадающих с юга в крупные внутренние озера, тоже относится к атлантическому климатическому периоду. На большей части территории все же продолжались восходящие движения земной коры.

Послеледниковое поднятие отчетливо выражается также в строении и развитии долин (Мийдел, 1967; Орвику, 1960, 1969; Linkrus, 1963 и др.). О послеледниковом поднятии земной коры свидетельствуют, например, значительный врез рек Северной Эстонии (в нижнем течении до 30 м), малая мощность аллювиальных отложений (в нижнем течении $1-2$, редко 3 м), широкое развитие эрозионных пойм, расходящиеся в направлении устьев рек спектры эрозионных террас и т. д.

$\mathrm{Ha} \mathrm{основании} \mathrm{сопоставления} \mathrm{данных} \mathrm{изучения} \mathrm{современных} \mathrm{движений}$ земной коры и долин в бассейне р. Пярну нами были выделены районы врезания и аккумуляции (рис. 2), образование которых связывалось с различным характером современных движений земной коры в шарнирной полосе (Мийдел, 1966).

Изложенный материал указывает еце раз на очень сложный характер поздне- и послеледниковых движений земной коры на территории Әстонии, все возможности изучения которых еще далеко не исчерпаны. Для определения истинных амплитуд и скоростей поднятия необходимо, в первую очередь, найти способ для выделения эвстатического фактора из суммарного поднятия.

\section{ЛИТЕ Р А Т Р Р А}

Г у де л и с В. К. 1972. Современные, поздне- и послеледниковые движения земной коры Прибалтики. Современные движения земной коры. Тезисы докл. Таллин.

К а я к К. 1959. Геология долины реки Вяйке-Эмайыги. Уч. зап. Тартуск, гос. ун-та, вып. 75 . 
Кессел Х. Я. 1961. Древние береговые образования бассейна Балтийского моря в Эстонской ССР. Тр. Ин-та геол. АН ЭССР, VIII.

К ессел Х., Пунни н г Я.-М. 1969 а. Об абсолютном возрасте голоценовых трансгрессий Балтики на территории Эстонии. Изв. АН ЭССР, Хим. Геол., 18, № 2.

Кессел Х., Пунн и нг Я.-М. 1969 б. О распространении и стратиграфии отложений Иольдиевого моря на территории Эстонии. Изв. АН ЭССР, Хим. Геол., 18, № 2.

Кес сел Х. Я., Р а у к а с А. В. 1967. Прибрежные отложения Анцилового озера и Литоринового моря в Эстонии. Таллин.

Лилиенберг Д. А., Сетунск а Л. Е., Благоволин Н. С., Горелов С. К., Н иконов А. А., Розанов Л. Л., Серебрянный Л. Р., Филькин В. А. 1972. Морфоструктурный анализ современных вертикальных движений Европейской части СССР. Геоморфология, № 1.

М е ще ряков Ю. А. 1961. Молодые тектонические движения и эрозионно-аккумулятивные процессы северо-западной части Русской равнины. М.

М еще ряков Ю. А. 1965. Структурная геоморфология равнинных стран. М.

М и йд ел А. 1966. О связи между современными движениями земной коры и эрозионноаккумулятивной деятельностью рек Эстонии. Изв. АН ЭССР, Сер. физ.-матем. и техн Н., 15, № 1 .

М и й дел А. 1967. Некоторые черты геоморфологии долин Северной Эстонии. Изв. АН ЭССР, Хим. Геол., 16, № 3.

О р в и у К. К. 1960. О неотектонических движениях в Эстонской ССР на основе геологических данных. В сб.: Неотектонические движения в Прибалтике. Тарту.

О рв ику К. К. 1969. Влияние поднятия земной коры на геолого-геоморфологическое развитие территории Эстонии в позднеледниковое время и в голоцене. В сб.: Новейшие движения, вулканизм и землетрясения материков и дна океанов. $M$.

О р в и к у Л. Ф. 1958. Новые данные о геологии озера Выртсъярв. Тр. Ин-та геол. АН ЭССР. III. Таллин.

Пярна К. 1962. О геологии Балтийского приледникового озера и крупных местных приледниковых озер на территории Эстонии. Автореф. канд. дисс. Таллин.

Р а ук а с А., Р я х н и Э. 1969 . О геологическом развитии впадины и бассейнов Чудского и Псковского озер. Изв. АН ЭССР, Хим. Геол., 18, № 2.

Р а ук а с А., Р яхни Э., М и й дел А. 1971. Краевые ледниковые образования Северной Эстонии. Таллин.

С а м м е т Э. Ю. 1965. Основные этапы развития некоторых типов приледниковых озер в заладной части Ленинградской и Псковской областей. Мат-лы к симп. по истории озер Северо-Запада. Л.

У т т е р Л. Р. 1964. Попытка геологической интерпретации схемы изобаз территории Эстонской ССР. В сб.: Современные и новейшие движения земной коры в Прибалтике. Вильнюс.

Хейн с ал у Ю., С ильдв ээ Х. 1971. О связях между неотектоническими и современными дифференцированными движениями и зонами разломов в Северо-Восточной Эстонии. Изв. АН ЭССР, Хим. Геол., 20, № 3.

Gudel is V. K. 1961. Latest and recent vertical Earth crust movements and the morphology of the sea-coast of the East Baltic area. Bull. geol., No. 62 .

$\mathrm{H}$ ang E., Liblik T., Linkrus E. 1964. On the relations between Estonian valley terraces and lake and sea levels in the Late-Glacial and Holocene periods. Tartu Riikliku Olik. Toimet., Nr. 156.

$\mathrm{H}$ a usen H. 1913. Ober die Entwicklung der Oberflächenformen in den russischen Ostseeländern und angrenzenden Gouvernements in der Quartärzeit. Fennia, $34, \mathrm{Nr} .3$.

Hörnsten A. 1964. Angermanlands kustland under isavsmältningsskedet preliminärt meddelande. Geol. Fören. Stockh. Förh., 86, 181-205.

Liblik T. 1966. Jooni Piusa oru geomorfoloogiast. Eesti Geograafia Seltsi Aastaraamat, 1964/1965. Tallinn.

L inkrus E. 1963. Valgejōe alamjooksu oru geomorfoloogiast. Eesti Geograafia Seltsi Aastaraamat, 1962. Tallinn.

Lundqvist J. 1965. The Quaternary of Sweden. In: The Geologic Systems. The Quaternary, 1. New York-London-Sydney.

Mörner N.-A. 1969. The Late Quaternary History of the Kattegatt Sea and the Swedish West Coast: deglaciation, shore level displacement, chronology, isostasy and eustasy. Sver. Geol. Unders., Ser. C., Nr. 640.

Mörner N. A. 1971. Eustatic changes during the last 20,000 years and a method of separating the isostatic and eustatic factors in an uplifted area. Palaeogeogr., Palaeoclim., Palaeoecol., 9, 153-181.

Orviku K. 1961. Neotektoonika osast Eesti geoloogilises arengus antropogeeniajastul. ENSV TA Geol. Inst. Uurimused, VII.

$\mathrm{R}$ a m s a y W. 1929. Niveauverschiebungen, eisgestaute Seen und Recession des Inlandeises in Estland. Fennia, 52, Nr. 2. 
$\mathrm{Z}$ heln in G. 1966. On the recent movements of the Earth's surface in the Estonian SSR Suomal. Tiedeakat. toimit. Sarja A, III. Geol.-Geogr., 90.

Thom son P. W. 1939. Ulevaade Eesti soodest. Eesti Loodus, nr. 2/3.

Ннститут геологии

Академии наук Эстонской ССР
Поступила в редакцию 23/I 1973

\section{HELGI KESSEL, A. MIIDEL}

\section{HILIS- JA JÄÄAJAJÄRGSETEST MAAKOORE LIIKUMISTEST EESTIS}

Artiklis iseloomustatakse hilis- ja jääajajärgseid makoore summaarseid liikumisi Eestis suurte jääpaisjärvede ja Balti mere rannajoonte muutuste (joon. 1) pōhjal. Kuna Eesti kohta puuduvad vajalikud andmed, ei ole seejuures arvestatud mere taseme eustaatilist tõusu.

Suure jääpaisjärve $\left(\mathrm{G}_{1}\right)$ tekkest alates kuni preboreaalse Joldiamere $\left(\mathrm{Y}_{11}\right)$ kujunemiseni kerkis Loode-Eesti 2450 aasta jooksul $65 \mathrm{~m}$ (joon. 2), jääajajärgse 9600 aasta vältel aga vaid $50 \mathrm{~m}$ (joon. 2). Tallinna lähedal oli kerkimise keskmine kiirus neil aegadel vastavalt 26,5 ja $4,2 \mathrm{~mm} /$ aastas.

Vanade rannajoonte gradientide muutumise uurimisel selgus (joon. 3), et kōnesolev kerkimine on toimunud ebaühtlaselt. Eriti järsult on tema kiirus vähenenud atlantilise kliimastaadiumi lōpul (joon. 3).

Juhitakse tähelepanu sellele, et kerkimise suuna asimuut on aegade kestel muutunud. Balti jääpaisjärve ajal oli see $335^{\circ}$, tänapäeval aga umbes $310^{\circ}$. Oletatakse, et see on seotud Fennoskandia kerkimise tsentri nihkumisega hilisjääajal ja pärast jääaega.

Avaldatakse arvamust, et Balti jääpaisjärve rannajoonte painde (joon. 1) pōhjal kindlaks tehtud mobiilne kirdesuunalirie tsoon (joon. 2) võis olla liikuv kogu holotseeni vältel.

\section{HELGI KESSEL, A. MIIDEL}

\section{ON THE LATE AND POST-GLACIAL CRUSTAL MOVEMENTS IN ESTONIA}

In the present paper the Late and Post-Glacial crustal movements are discussed on the basis of raised coastal forms of glacial lakes and the Baltic Sea (Fig. 1). Eustatic rise of sea level has not been taken into account because corresponding data are lacking in respect to Estonia.

Since the existence of the glacial lake $G_{1}$ up to the formation of the Preboreal Yoldia Sea $\left(\mathrm{Y}_{11}\right)$, during the 2450 years the territory of North-Western Estonia rose $65 \mathrm{~m}$ (Fig. 2), at least. In the Post Glacial, during the past 9600 years, the same area has risen about $50 \mathrm{~m}$ (Fig. 2). In the surroundings of Tallinn the average rate of the uplift in the above-mentioned periods was correspondingly 26.5 and $4.2 \mathrm{~mm}$ per year.

By means of the changes in the gradients of the shorelines (Fig. 3) it has been found that the uplift proceeded unevenly. The rate of the land upheaval decreased abruptly at the end of the Atlantic Period (Fig. 3).

Attention is drawn to the fact that the direction of tilting has been changing (in time). At the time of the existence of the Baltic Ice Lake it was $335^{\circ}$, but at the present time it is about $310^{\circ}$. The authors suppose that this phenomenon may be connected with the shifting of the Fennoscandian upwarping centre during the Late and Post Glacial Time.

The authors assume that the NE-directed tectonic zone (Fig. 2) distinguished by the bending of the shorelines of the Baltic Ice Lake (Fig. 1) could have been active not only in the Late Glacial Time, but also throughout the whole Holocene. 